\title{
Ten years of the journal, Aquatic Ecology: an appraisal
}

\author{
Ramesh D. Gulati
}

Published online: 22 May 2007

(C) Springer Science+Business Media B.V. 2007

Aquatic Ecology recently completed a decade of publication from the time it was reorganised and its name was changed. I think it is long enough time for both a stocktaking and to have a retrospective look at the developments, and for the future perspectives. In March 1997, the name of the Netherlands Journal of Aquatic Ecology was changed to Aquatic Ecology (Vol.31, 1). As a member of the executive committee of the Netherlands Society for Aquatic Ecology (NVAE; now the Netherlands-Flemish Ecology Society, NecoV), I consistently pleaded for reforms comprising restructuring of the journal not only by changing its name but also by redefining the journal's scientific scope, and inducing changes in the editorial procedures. The main aim of these suggested changes was to attract more and better quality manuscripts, and improve the review procedures. To achieve these goals, the journal's distribution world-wide and global readership needed to be expanded. These planned changes made it imperative to simultaneously look for a good, international scientific publisher in aquatic science. Kluwer Academic Publishers (now Springer), Dordrecht, was the obvious first choice. We were successful in our discussions with the publishers. Thus, the appearance in 1997 of Volume 31(1) of Aquatic Ecology in the Netherlands marked the start of a new era for the journal.

\section{R. D. Gulati $(\square)$}

NIOO/Centre of Limnology, P.O. Box 1299, 3600 BG

Maarssen, The Netherlands

e-mail: r.gulati@nioo.knaw.nl

\section{A new start}

Going back to the start of the rechristening of the journal may sound like telling my story vis-à-vis the journal. In my proposal for changes in the scientific scope, quality of manuscripts, new publishers of the journal, etc., I had full backing of the NecoV. I, however, did not fully appreciate that there was yet another pleasant surprise for me in the offing, an opportunity to serve the journal as its editor-in-chief. Thanks to Prof. Joop Ringelberg, the famous Dutch ecologist, and NecoV board members, who all supported my nomination for the chief editorship of Aquatic Ecology. I readily accepted the offer, considering that with just three years to retire from my position as a senior research scientist at the Netherlands Institute of Ecology (NIOO), I would have more free time to do the editorial work. My new task was made easy with the help of two associated editors: Karel Essink and Niels De Pauw. We first radically reorganised the journal by spelling out the wide field of aquatic ecology, defining some subject areas in which the journal would give preference in accepting manuscript submissions. Secondly, we refurbished as well as enlarged the editorial board in commensurate with the journal's new scientific scope and needs. The new editorial board retained some of the former, experienced editorial board members but I invited several internationally wellknown scientists with editorial experience to join the editorial board. In short, together, we three formed a 
good managing editorial team to give the journal a head-on start. We could not have started off better than publish the proceedings of an international symposium entitled "The Future of Plankton Research", (21 March 1997), as a commemoration volume to Prof. Joop Ringelberg on his retirement from the University of Amsterdam.

The journal has now come a long way from the point we got it going a decade ago. Through this ten year period, the four quarterly issues of the journal have appeared every year on schedule and uninterrupted. I have been learning from the feedback, that the international readership has been steadily increasing through both the hard copy and online subscriptions. This is apparently connected with the consistently reasonable and good quality of papers published. Strikingly, the number of papers published in the journal annually does not show a bias towards a country or a geographical region but are well spread out country wise. We do not do concessions, nor sacrifice quality in any way during the review process. As a managing editorial team of three persons, we stringently follow the comments and recommendations generally of three peers for each MS received. It is, indeed, hard for us as editors to decide the fate of a manuscript when reviewers are equivocal in their recommendations. It is not an exception to get three concurrent recommendations on the same manuscript such as 'reject', 'major revision' and 'minor revisions'. In such cases, it is invariably also the irritation caused by poor readability due to below par language and inability of some authors to express their ideas more clearly due to lack of experience in writing, or perhaps the reviewer's foregone conclusion or perhaps chauvinism. I believe that some of such authors can be helped if reviewers could find a little extra time. Instead, quite a few reviewers advice to take help from native speaker during revision. The italicised expression has become a commonplace expression, a cliché these days.

\section{Achievements, manuscript inflow and acceptance rate}

It took about six years after Aquatic Ecology was reorganised that it became accessible on the Web of Science. Following this in 2005, the journal reached another milestone when it received an impact factor
(0.779), based on papers published in 2003 and 2004 and cited in 2005. Although it is a modest accomplishment, this is an impetus that seems to be having a significant influence on the monthly MS inflow, which has since early 2006 increased by nearly $60 \%$. However, the manuscript rejection rate during the review process has also concomitantly climbed precipitously, from about $40 \%$ until 2005 to nearly $70 \%$ since early last year. On one hand, it is a good sign that the quality of the accepted manuscripts is being scrupulously maintained, but on the other, there is cause for concern. Incidentally, this noticeable rise in rejection rates can be attributed predominantly to increased inflow of manuscripts from certain regions. Despite the good quality of data contained in the manuscripts from these areas, both the culture and experience of the scientific writing (in English) are relatively young and new. As an Editor, I feel that in some such border-line cases, both the reviewers and editors have an added moral responsibility to help. In most other cases, however, the quality of manuscripts must be improved considerably at the source, namely, by the authors before submitting them to an international journal.

\section{Special issues}

We also published several thematic issues of the journal usually one per year, the so-called Specials, during the last 10 years. These issues have covered a variety of themes that vary from the limnology of Lake Myvatn in Iceland in the extreme north of Europe, to lakes in North Africa. Some other specials dealt with, e.g. the biology of small ephemeral ponds, problems of eutrophication of large estuarine areas in Europe and a long-term ecosystem study on the saline lake Shira in Siberia, Russia. Three more Specials are in preparation: on Ecological Informatics Applications in Water Management, Limnology in Latin America and EU Water Framework Directive (WFD).

\section{Invitation to contribute papers, do review work}

The readers are invited to contribute papers based on original research, opinion papers and letters to the editor based on reaction to papers published recently 
in the journal. Both submitted review papers relating to research in aquatic ecology and invited review papers are considered for publication. There is a provision to award the NecoV Dresscher Prize annually to the author(s) of best paper from the Netherlands and Belgium (Vlaanderen region). The journal also accepts book reviews in limnology, oceanography and other aquatic fields for publication. Depending on the space available, special thematic papers (e.g. brief proceedings of international conferences) are also considered for publication as a "special issue".

We are on the look out for further improvements in the review process and for expanding the editorial board by including several 'subject editors' who can handle the manuscripts in the areas of their expertise and report their recommendations to their managing editorial board. Those having some experience and interested for the 'job' of subject editor can contact me by e-mail, giving a brief $\mathrm{CV}$ with expertise. I also look forward to receiving suggestions for my own replacement in the near future (the position of editor- in-chief is open to only the Dutch and Flemish members of $\mathrm{NecoV}$ ).

Acknowledgements I express gratitude, also on behalf of my colleagues Niels De Pauw and Koos Vijverberg, to the members of the consulting editorial board but certainly also to more than 400 reviewers, who accepted our invitations electronically during the last 17 months and reviewed and rereviewed manuscripts. It is both alarming and frustrating to note that about one-third of the reviewers declined the invitations since we switched on to Electronic Manager in December 2005. Although in is most such cases, the inability of the reviewers is understandable, it is inexplicable in some other cases. I do realise that it is not always physically possible for us, the managing editorial team, to invite reviewers personally rather than through the Electronic Manager. The electronic invitation system seems to work efficiently, despite that it is more perfunctory and impersonal. Last, I am thankful to the Netherlands Institute of Ecology for allowing me for all these ten years to operate as an editor using my erstwhile study room at the Centre of Limnology as well as other facilities available at the Centre for my editorial office. I must also thank the NecoV Executive Committee (Section Aquatic Ecology) and Springer Publishers for their cooperation and flexibility in the schedule for the regular issues and specials issues. 